\title{
Overview of prevalence, trends, and outcomes of post myocardial infarction mechanical complications
}

\author{
Dhruv Mahtta ${ }^{1}$, Ibrahim Mohammed ${ }^{2}$, Islam Y. Elgendy ${ }^{2}$ \\ ${ }^{1}$ Section of Cardiology, Baylor College of Medicine, Houston, TX, USA; ${ }^{2}$ Department of Medicine, Weill Cornell Medicine-Qatar, Doha, Qatar \\ Correspondence to: Islam Y. Elgendy, MD, FESC, FACC, FAHA, FSCAI, FACP. Assistant Professor of Medicine, Weill Cornell Medicine-Qatar, \\ Education City, Qatar Foundation, PO Box 24144, Doha, Qatar. Email: iyelgendy@gmail.com.
}

Submitted Jul 05, 2021. Accepted for publication Jan 11, 2022.

doi: $10.21037 /$ acs-2021-ami-12

View this article at: https://dx.doi.org/10.21037/acs-2021-ami-12

Although infrequently encountered in contemporary clinical practice, post-acute myocardial infarction (AMI) mechanical complications are associated with considerable mortality and morbidity (1). These complications include free-wall rupture (FWR), ventricular septal rupture (VSR), and papillary muscle rupture (PMR) (2). As the landscape of AMI treatment has evolved over the past decades with a focus on reducing ischemic time and timely reperfusion via primary percutaneous coronary intervention (pPCI), the mortality rates related to AMI have declined (3). However, a similar decline in mortality rates associated with post-AMI mechanical complications has not been observed (4).

In a United States observational analysis of $>9$ million hospitalizations spanning from 2003-2015, the rates of mechanical complications were approximately $0.27 \%$ among patients with ST-elevation myocardial infarction (STEMI) and $0.06 \%$ among patients with non-ST-elevation myocardial infarction (NSTEMI), without any observed declines in secular trends (4). Similar findings were observed in an analysis from the Spanish National Health System between 2010-2015 which showed that the prevalence of post-MI mechanical complications was $0.35 \%$ (5). Among the various post-AMI mechanical complications, VSR remains the most common complication with an estimated prevalence of $0.17 \%$ to $0.91 \%$, while the prevalence of PMR and FWR are $~ 0.05 \%$ to $0.26 \%$ and $0.01 \%$ to $0.52 \%$, respectively (6).

The lack of decline in the rates of post-AMI mechanical complications in the current era of reperfusion therapy might be attributed to several factors. With advancement in technology and reliance on multimodality cardiac imaging, this plateau might be secondary to increased recognition and diagnosis of mechanical complications, despite a decrease in the prevalence of these complications. Due to the implementation of quality improvement processes and enhanced streamline care of AMI patients, another plausible explanation of this observed plateau might be a rise in the number of patients with late-presentation AMI, who portend a higher risk of mechanical complications. Variability in ischemic time and delayed recognition of symptoms in certain patient subgroups such as elderly and women contribute to the lack of decline in the incidence of post-AMI mechanical complications. The observed higher prevalence of post-AMI mechanical complications among many centers during the early waves of the COVID-19 pandemic further supports this hypothesis (7).

Despite advances in pharmacological management of AMI patients and use of mechanical circulatory support devices among patients with cardiogenic shock, inhospital mortality rates among patients with mechanical complications has remained significantly high ( 40-50\%) and has not declined over the past 2 decades $(4,8,9)$. While factors such as advanced age, female sex, STEMI presentation, TIMI 0 or I flow, cardiogenic shock, and cardio-respiratory failure are linked with higher in-hospital mortality $(4,8)$, centers with cardiac intensive care units and greater experience seem to have better outcomes (5). Importantly, some observational studies have suggested that surgical repair is associated with improved in-hospital mortality $(2,4)$. However, these data are likely limited due to inherent selection and ascertainment bias since patients undergoing surgical repair are often clinically stable, non-frail, and without severe end-organ failure. As such, society guidelines recommend surgical management 
if feasible (10). Timing of surgical intervention among these patients due to fragility of the endocardial tissue, and indication for percutaneous repair, remain topics of ongoing investigations.

While there are several registry-based studies providing evidence regarding the temporal trends and prevalence of post-AMI mechanical complications, the current prevailing data regarding outcomes and utility of surgical intervention are limited to non-randomized data. Registry-based initiatives are needed such as CAUTION (NCT03848429) which is an international, multicenter registry aiming to evaluate surgical management and post-operative outcomes, survival, and quality-of-life measures among patients undergoing cardiac surgery for post-AMI mechanical complications. In another sub-study of CAUTION (CautionCov19; NCT04813692), the investigators aim to examine the impact of the COVID-19 pandemic on the outcomes, incidence, and management of post-AMI mechanical complications. Besides efforts to delineate the timing and outcomes associated with surgical repair, equal focus is needed in preventing post-AMI mechanical complications. Dedicated efforts to increase public awareness of ischemic symptoms to shorten the duration between symptom onset and medical evaluation may assist in reducing the risk of mechanical complications. In addition to patient factors, continued efforts in streamlining STEMI care, early recognition of AMI, and curbing pre- and inhospital delays prior to reperfusion therapy are encouraged. Lastly, risk stratifying patients with late presentation AMI or those with inadequate revascularization (non-TIMI III flow post pPCI) using timely echocardiographic assessment and having high clinical suspicion for early identification of mechanical complication may also serve prudent in the management of these patients.

\section{Acknowledgments}

Funding: None.

\section{Footnote}

Conflicts of Interest: Dr. IYE has disclosures unrelated to this manuscript content including receiving research grants from Caladrius Biosciences, Inc. The other authors have no conflicts of interest to declare.

Open Access Statement: This is an Open Access article distributed in accordance with the Creative Commons Attribution-NonCommercial-NoDerivs 4.0 International License (CC BY-NC-ND 4.0), which permits the noncommercial replication and distribution of the article with the strict proviso that no changes or edits are made and the original work is properly cited (including links to both the formal publication through the relevant DOI and the license). See: https://creativecommons.org/licenses/by-nc-nd/4.0/.

\section{References}

1. Goldsweig AM, Wang Y, Forrest JK, et al. Ventricular septal rupture complicating acute myocardial infarction: Incidence, treatment, and outcomes among medicare beneficiaries 1999-2014. Catheter Cardiovasc Interv 2018;92:1104-15.

2. French JK, Hellkamp AS, Armstrong PW, et al. Mechanical complications after percutaneous coronary intervention in ST-elevation myocardial infarction (from APEX-AMI). Am J Cardiol 2010;105:59-63.

3. Virani SS, Alonso A, Aparicio HJ, et al. Heart Disease and Stroke Statistics-2021 Update: A Report From the American Heart Association. Circulation 2021;143:e254-e743.

4. Elbadawi A, Elgendy IY, Mahmoud K, et al. Temporal Trends and Outcomes of Mechanical Complications in Patients With Acute Myocardial Infarction. JACC Cardiovasc Interv 2019;12:1825-36.

5. Sanmartín-Fernández M, Raposeiras-Roubin S, AnguitaSánchez M, et al. In-hospital outcomes of mechanical complications in acute myocardial infarction: Analysis from a nationwide Spanish database. Cardiol J 2021;28:589-97.

6. Gong FF, Vaitenas I, Malaisrie SC, et al. Mechanical Complications of Acute Myocardial Infarction: A Review. JAMA Cardiol 2021;6:341-9.

7. Fardman A, Zahger D, Orvin K, et al. Acute myocardial infarction in the Covid-19 era: Incidence, clinical characteristics and in-hospital outcomes-A multicenter registry. PLoS One 2021;16:e0253524.

8. Lanz J, Wyss D, Räber L, et al. Mechanical complications in patients with ST-segment elevation myocardial infarction: A single centre experience. PLoS One 2019;14:e0209502.

9. Puerto E, Viana-Tejedor A, Martínez-Sellés M, et al. Temporal Trends in Mechanical Complications of Acute Myocardial Infarction in the Elderly. J Am Coll Cardiol 2018;72:959-66. 
10. Ibanez B, James S, Agewall S, et al. 2017 ESC Guidelines for the management of acute myocardial infarction in patients presenting with ST-segment elevation: The Task Force for the management of acute myocardial infarction

Cite this article as: Mahtta D, Mohammed I, Elgendy IY. Overview of prevalence, trends, and outcomes of post myocardial infarction mechanical complications. Ann Cardiothorac Surg 2022;11(3):322-324. doi: 10.21037/acs-2021ami-12 in patients presenting with ST-segment elevation of the European Society of Cardiology (ESC). Eur Heart J 2018;39:119-77. 